\title{
Understanding the Risk of Human Immunodeficiency Virus (HIV) Virologic Failure in the Era of Undetectable Equals Untransmittable
}

\author{
Jayleen K. L. Gunn ${ }^{1,2} \cdot$ Wendy Patterson $^{1} \cdot$ Bridget J. Anderson ${ }^{1} \cdot$ Carol-Ann Swain ${ }^{1,3}$ (1)
}

Accepted: 31 December 2020 / Published online: 13 January 2021

(c) The Author(s) 2021

\begin{abstract}
The "Undetectable $=$ Untransmittable" campaign indicates that persons living with Human Immunodeficiency Virus (HIV) who maintain a suppressed viral load cannot sexually transmit the virus. However, there is little knowledge of the percent of individuals at a population level who sustain viral suppression long term. The aims of this study were to: (1) establish a baseline of persons living with diagnosed HIV who resided in New York and had consecutive suppressed viral load tests; (2) describe the risk of virologic failure among those who were consecutively suppressed; and (3) gain an understanding of the length of time between consecutive viral suppression to virologic failure. A total of 102,339 New Yorkers aged 13-90 years were living with diagnosed HIV at the beginning of 2012; $47.9 \%$ were consecutively suppressed (last two HIV viral load test results from 2010-2011 that were $<420$ days apart and $<200$ copies $/ \mathrm{mL}$ ). Of consecutively suppressed individuals, $54.3 \%$ maintained viral suppression for the entire study period and 33.6\% experienced virologic failure during the study period. Among persons who experienced virologic failure, $82.6 \%$ did so six or more months after being consecutively suppressed. Our findings support the need for ongoing viral load monitoring, adherence support, and ongoing risk reduction messaging to prevent forward HIV transmission.
\end{abstract}

Keywords HIV/AIDS · Viral suppression $\cdot$ Surveillance $\cdot$ Viral load

\section{Introduction}

Viral suppression of human immunodeficiency virus (HIV) is the pillar of the Undetectable $=$ Untransmittable $(\mathrm{U}=\mathrm{U})$ campaign, which states that persons living with diagnosed HIV (PLWDH) cannot sexually transmit the virus when they are virally suppressed $[1,2]$. Based on the evidence [3-12], over 750 organizations from 60 countries have endorsed the campaign [2, 13]. In 2017, New York State (NYS) became the first state Department of Health (DOH) in the United States (US) to endorse $\mathrm{U}=\mathrm{U}[14]$.

The availability of highly effective treatment regimens with fewer side effects has enabled HIV viral suppression

Carol-Ann Swain

carol-ann.swain@health.ny.gov

New York State Department of Health, Albany, NY, USA

2 United States Public Health Service, Washington, USA

3 Department of Health, AIDS Institute, Bureau of HIV/AIDS Epidemiology, New York State, Corning Tower, Albany, NY, USA rates in the US to rise in recent years [15]. While promising, most clinical and surveillance studies evaluate HIV viral suppression based on the last viral load (VL) test result reported [15-18]. This cross-sectional approach may overestimate the number of persons who are stably suppressed and can be misleading in regards to $\mathrm{U}=\mathrm{U}$ [18].

The empirical evidence in support of $U=U$ has focused on the individual and community level benefits of viral suppression [3-12]. There is little understanding about long term viral suppression at the population level. The aims of this study were to: (1) establish a baseline of persons living with diagnosed HIV who resided in NYS and had consecutive suppressed VL results (i.e., the last two HIV VL results $<200$ copies $/ \mathrm{mL}$ ) from 2010-2011; (2) describe the risk of virologic failure among those who were consecutively suppressed; and (3) gain an understanding of the length of time between consecutive viral suppression to virologic failure. 


\section{Methods}

The data for this retrospective cohort study were extracted from the NYSDOH HIV Surveillance System. The surveillance system, by public health law and regulation, receives electronically the results of all HIV related laboratory testing conducted for individuals residing in, or receiving HIV-related care within the state; reporting exemptions exist including that federal facilities report in the spirit of cooperation. The surveillance system includes reports for all persons diagnosed and reported with AIDS in NYS since 1981 and with HIV since 2000. The data for this study encompassed seven years, 2010-2016. HIV VL results with specimen collection dates from January 1, 2010-December 31, 2011 were used to determine initial viral suppression and study entry; sustained viral suppression was evaluated from 2012 through 2016. Reported HIV VL laboratory test results were used as a proxy for HIV medical care encounters [19].

Individual level data elements extracted from the surveillance system included: HIV diagnosis date; sex assigned at birth; age as of January 1, 2012; HIV transmission risk category; race and ethnicity; and collection dates and results of HIV VL tests from 2010-2016. Only adults and adolescents (aged 13 years and older at the beginning of 2012) were included [20]. HIV transmission risk factor information was summarized according to the CDC algorithm [21]. This risk hierarchy is based on the probability of transmission as well as the prevalence of infection among persons to whom these categories apply. HIV transmission risk categorization considers only those events that occurred prior to HIV diagnosis and may not reflect current risk behaviors. Males with a history of male-to-male sexual contact (MSM) were classified as MSM regardless of an additional history of male-tofemale sexual contact. Persons with a history of injection drug use (IDU) were classified as IDU, regardless of their sexual history, except for MSM, who were classified as MSM/IDU. Other HIV risk acquisition categories include blood transfusion, perinatal exposure, and risk factor not reported or not identified. Persons' were categorized by race and ethnicity as non-Hispanic white, non-Hispanic black, Hispanic; for this analysis, individuals categorized as non-Hispanic multi-race, non-Hispanic Native American, and non-Hispanic Asian/Pacific Islander were grouped in a category designated as other races.

Virologic failure was defined as an HIV VL $\geq 200$ copies $/ \mathrm{ml}$. The number of days from the last suppressed VL to the first failure was calculated. To be inclusive of individuals with non-routine HIV care (i.e., minimal reported VL results), participants were censored if there was a gap of $\geq 420$ days between VL test results. Participants were also censored at death or at study end (i.e., December 31, 2016) if viral suppression was sustained throughout the study period. Univariate and multivariable Cox proportional hazards were calculated to examine the association between virologic failure and the following covariates: sex assigned at birth, race/ethnicity, age as of January 1, 2012, and mode of HIV transmission. Only individuals who met the following criteria were included in the study cohort: (1) diagnosed with HIV prior to 2010; (2) age $\geq 13$ and $\leq 90$ years old on January 1, 2012; (3) presumed to reside in NYS at beginning of 2012; (4) had $\geq 1$ VL test result after 2011; and, (5) achieved consecutive viral suppression-defined as the results of the last two VLs from 2010-2011, $<200$ copies/mL, and $<420$ days apart. A secondary analysis among individuals who experienced virologic failure was performed to categorize the length of time between consecutive viral suppression and virologic failure. All analyses were performed using SAS 9.4 (Cary, NC). The data reported in this study were under a comprehensive HIV surveillance IRB exemption.

\section{Results}

In 2011, there were 102,339 PLWDH aged 13-90 years residing in NYS. PLWDH were predominately male (69.4\%), aged 40-59 years (64.1\%), had MSM and MSM/ IDU transmission risk (38.4\%), and were persons of color (non-Hispanic black 40.5\%; Hispanic 32.2\%). Overall, $47.9 \%(49,021)$ were consecutively virally suppressed (Table 1). Of consecutively suppressed individuals, 54.3\% $(26,637)$ maintained viral suppression for the entire study period, $33.6 \%(16,465)$ experienced virologic failure during the study period, $7.7 \%$ (3782) experienced a reported viral load gap of $\geq 420$ days, and $4.4 \%$ (2137) died during the study period before experiencing virologic failure or a gap of $\geq 420$ days. There were 1352 deaths among the 16,465 individuals who experienced virologic failure. The median time to virologic failure for these individuals was 362 days.

Virologic status varied by participant characteristic. Consecutive viral suppression increased with age: $45.0 \%$ of persons aged 13-17 years achieved consecutive viral suppression compared to $60.3 \%$ of persons aged $60+$ years. Roughly half of individuals with heterosexual (48.7\%) and MSM (50.4\%) transmission risk achieved consecutive viral suppression. More than half of non-Hispanic whites (55.2\%) achieved consecutive viral suppression whereas $48.5 \%$ of Hispanics and $43.0 \%$ of non-Hispanic blacks achieved consecutive viral suppression. Among those who achieved consecutive suppression, virologic failure was highest among the youngest age categories ( $52.6 \%$ for persons age 13-17 years and $41.9 \%$ for persons age 18-29 years), for persons with a history of IDU (40.7\%), and persons of color (38.3\% 
Table 1 Summary of study population

\begin{tabular}{|c|c|c|c|c|c|c|c|c|c|c|c|c|}
\hline \multirow[t]{4}{*}{ Subgroup } & \multirow{3}{*}{\multicolumn{2}{|c|}{ Overall population $^{\mathrm{a}}$}} & \multirow{3}{*}{\multicolumn{2}{|c|}{$\begin{array}{l}\text { Consecutively } \\
\text { suppressed }{ }^{\text {b study }} \\
\text { start }\end{array}$}} & \multicolumn{8}{|c|}{ Results of consecutively suppressed population } \\
\hline & & & & & & & Censore & & & & & \\
\hline & & & & & \multicolumn{2}{|c|}{$\begin{array}{l}\text { Unsuppressed dur- } \\
\text { ing the study }\end{array}$} & \multicolumn{2}{|c|}{$\begin{array}{l}\text { Sustained suppres- } \\
\text { sion throughout } \\
\text { study }\end{array}$} & \multicolumn{2}{|c|}{$\begin{array}{l}\geq 420 \text { days } \\
\text { between viral } \\
\text { load tests }\end{array}$} & \multicolumn{2}{|l|}{ Death } \\
\hline & $\mathrm{n}$ & $\%$ & $\mathrm{n}$ & $\%$ & $\mathrm{n}$ & $\%$ & $\mathrm{n}$ & $\%$ & $\mathrm{~N}$ & $\%$ & $\mathrm{n}$ & $\%$ \\
\hline Total & 102,339 & & 49,021 & & 16,465 & & 26,637 & & 3,782 & & 2,137 & \\
\hline \multicolumn{13}{|l|}{ Sex assigned at birth } \\
\hline Male & 71,029 & 69.41 & 34,048 & 69.46 & 11,015 & 66.90 & 18,763 & 70.44 & 2,729 & 72.16 & 1,541 & 72.11 \\
\hline Female & 31,310 & 30.59 & 14,973 & 30.54 & 5,450 & 33.10 & 7,874 & 29.56 & 1,053 & 27.84 & 596 & 27.89 \\
\hline \multicolumn{13}{|l|}{$\operatorname{Age}^{c}$ in years } \\
\hline $13-17$ & 520 & 0.51 & 234 & 0.48 & 123 & 0.75 & 103 & 0.39 & 8 & 0.21 & 0 & 0.00 \\
\hline $18-29$ & 6,644 & 6.49 & 1,964 & 4.01 & 823 & 5.00 & 938 & 3.52 & 196 & 5.18 & 7 & 0.33 \\
\hline $30-39$ & 14,376 & 14.05 & 5,426 & 11.07 & 1,914 & 11.62 & 2,951 & 11.08 & 510 & 13.48 & 51 & 2.39 \\
\hline $40-49$ & 32,534 & 31.79 & 14,884 & 30.36 & 5,030 & 30.55 & 8,315 & 31.22 & 1,233 & 32.60 & 306 & 14.32 \\
\hline $50-59$ & 33,109 & 32.35 & 17,375 & 35.44 & 5,867 & 35.63 & 9,471 & 35.56 & 1,238 & 32.73 & 799 & 37.39 \\
\hline $60+$ & 15,156 & 14.81 & 9,138 & 18.64 & 2,708 & 16.45 & 4,859 & 18.24 & 597 & 15.79 & 974 & 45.58 \\
\hline \multicolumn{13}{|c|}{ HIV transmission risk category } \\
\hline Heterosexual & 29,945 & 29.26 & 14,572 & 29.73 & 5,079 & 30.85 & 7,943 & 29.82 & 1,064 & 28.13 & 486 & 22.74 \\
\hline IDU & 16,626 & 16.25 & 7,526 & 15.35 & 3,065 & 18.62 & 3,283 & 12.32 & 462 & 12.22 & 716 & 33.50 \\
\hline MSM+MSM/IDU & 39,324 & 38.43 & 19,830 & 40.45 & 5,769 & 35.04 & 11,696 & 43.91 & 1,722 & 45.53 & 643 & 30.09 \\
\hline Unknown/Other & 16,444 & 16.07 & 7,093 & 14.47 & 2,552 & 15.50 & 3,715 & 13.95 & 534 & 14.12 & 292 & 13.66 \\
\hline \multicolumn{13}{|l|}{ Race and Ethnicity } \\
\hline Non-Hispanic white & 20,883 & 20.41 & 11,536 & 23.53 & 2,575 & 15.64 & 7,334 & 27.53 & 1,137 & 30.06 & 490 & 22.93 \\
\hline Non-Hispanic black & 41,470 & 40.52 & 17,844 & 36.40 & 6,838 & 41.53 & 8,838 & 33.18 & 1,362 & 36.01 & 806 & 37.72 \\
\hline Hispanic & 32,930 & 32.18 & 15,963 & 32.56 & 5,899 & 35.83 & 8,384 & 31.48 & 1,012 & 26.76 & 668 & 31.26 \\
\hline Other & 7,056 & 6.89 & 3,678 & 7.50 & 1,153 & 7.00 & 2,081 & 7.81 & 271 & 7.17 & 173 & 8.10 \\
\hline
\end{tabular}

${ }^{a}$ Number of persons diagnosed with HIV in New York State aged 13-90 years

${ }^{\mathrm{b}}$ Consecutively Suppressed: results of the last two viral loads from 2010 to $2011,<200$ copies/ml, and $<420$ days apart

${ }^{\mathrm{c}}$ Age as of January 1, 2012

Table 2 Time to virologic failure* among those who experienced virologic failure

\begin{tabular}{lll}
\hline Time to virologic failure & $\mathrm{N}$ & $(\%)$ \\
\hline$\leq 6$ months & 2858 & $(17.4)$ \\
$>6$ months-1 year & 3225 & $(19.6)$ \\
1 + year-2 years & 4424 & $(26.9)$ \\
2+ years-3 years & 2526 & $(15.3)$ \\
3 + years-4 years & 1886 & $(11.4)$ \\
4 + years & 1546 & $(9.4)$ \\
Total & 16,465 & $(100 \%)$ \\
\hline
\end{tabular}

*Defined as $\geq 200$ copies/ml

non-Hispanic blacks and $37.0 \%$ for Hispanics). More than one-third of the consecutively suppressed individuals experienced virologic failure within one year of study start (17.4\% within the first six months, $19.6 \%$ between 7 to 12 months)
(Table 2). Approximately $20 \%$ of individuals who experienced virologic failure did so after 3 years of maintaining viral suppression. Among those experiencing virologic failure, the median time to virologic failure was $\mathbf{5 2 5}$ days (1.4 years). A shorter time to virologic failure was observed for individuals aged 18-29 years old (median $=448$ days) and those with a history of IDU (median $=469$ days); nonHispanic whites (median $=560$ days) experienced a longer time to virologic failure (not shown in tables) than persons of other race and ethnic groups. Most individuals (93\%, $\mathrm{n}=15,325)$ with virologic failure eventually achieved viral suppression during the study period; the median time to the first suppressed VL test result after virologic failure was 99 days.

In multivariable analysis, virologic failure decreased as age increased (age 30-39: adjusted [aHR] 0.70: 95\% CI 0.58-0.84; age 40-49: aHR, 0.69, 95\%CI 0.58-0.84; age 50-59, aHR 0.66, 95\% CI 0.55-0.80; and age 60+aHR 0.56, 
Table 3 Hazard ratio of virologic failure after achieving consecutive suppression

\begin{tabular}{|c|c|c|}
\hline Subgroup & $\begin{array}{l}\text { Univariate hazard ratio and } 95 \% \\
\text { confidence interval }\end{array}$ & $\begin{array}{l}\text { Multivariable hazard } \\
\text { ratio and 95\% confidence } \\
\text { interval }\end{array}$ \\
\hline \multicolumn{3}{|l|}{ Sex assigned at birth } \\
\hline Male & Ref & Ref \\
\hline Female & $1.14(1.10-1.18)$ & $0.99(0.94-1.04)$ \\
\hline \multicolumn{3}{|l|}{ Age group ${ }^{a}$} \\
\hline $13-17$ & Ref & Ref \\
\hline $18-29$ & $0.83(0.69-1.00)$ & $0.92(0.76-1.11)$ \\
\hline $30-39$ & $0.65(0.54-0.78)^{*}$ & $0.70(0.58-0.84)^{*}$ \\
\hline $40-49$ & $0.61(0.51-0.72)^{*}$ & $0.69(0.58-0.84)^{*}$ \\
\hline $50-59$ & $0.61(0.51-0.72)^{*}$ & $0.66(0.55-0.80)^{*}$ \\
\hline $60+$ & $0.53(0.44-0.63)^{*}$ & $0.56(0.47-0.68)^{*}$ \\
\hline \multicolumn{3}{|c|}{ HIV transmission risk category } \\
\hline Heterosexual & Ref & Ref \\
\hline IDU & $1.29(1.23-1.34)^{*}$ & $1.36(1.30-1.43)^{*}$ \\
\hline MSM + MSM/IDU & $0.82(0.80-0.85)^{*}$ & $0.92(0.87-0.98)^{*}$ \\
\hline Unknown/Other & $1.06(1.01-1.12)^{*}$ & $1.05(0.99-1.11)$ \\
\hline \multicolumn{3}{|l|}{ Race and Ethnicity } \\
\hline Non-Hispanic white & Ref & Ref \\
\hline Non-Hispanic black & $1.90(1.82-1.99)^{*}$ & $1.78(1.69-1.86)^{*}$ \\
\hline Hispanic & $1.79(1.71-1.87)^{*}$ & $1.66(1.58-1.74)^{*}$ \\
\hline Other & $1.48(1.38-1.58)^{*}$ & $1.38(1.29-1.48)^{*}$ \\
\hline \multicolumn{3}{|c|}{$\begin{array}{l}\text { Consecutively Suppressed: results of the last two viral loads from } 2010-2011,<200 \text { copies } / \mathrm{ml} \\
\text { and }<420 \text { days apart }\end{array}$} \\
\hline age as of January 1, & & \\
\hline
\end{tabular}

95\% CI 0.47-0.68) (Table 3). Persons with a history of IDU were more likely to experience virologic failure compared to individuals with heterosexual transmission risk (aHR 1.36, 95\% CI 1.30-1.43). In contrast, persons with MSM and MSM/IDU transmission risk were less likely to experience virologic failure compared to individuals with heterosexual contact transmission risk (aHR 0.92, 95\% CI:0.87-0.98). Race and ethnicity were related to risk of virologic failure, with non-Hispanic blacks (aHR 1.78, 95\% CI 1.69-1.86), Hispanics (aHR 1.66, 95\% CI 1.58-1.74), and individuals of other races (aHR1.38, 95\% CI 1.29-1.48) more likely to experience virologic failure than non-Hispanic whites. No differences were observed in time to virologic failure between males and females.

\section{Discussion}

This study demonstrated that about half (48\%) of New Yorkers aged 13-90 years living with diagnosed HIV achieved consecutive viral suppression. Of these, more than half (54\%) maintained suppression throughout the study period. One in three individuals who achieved consecutive viral suppression experienced virologic failure during study follow-up with more than one-third doing so within one year of the study start.

The proportion with virologic failure in this study was similar or higher than reported in previous research [22-25]. Researchers have cautioned that long term viral suppression may need to be defined with a sufficiently long time period to allow for true durable suppression to be observed [22]. For example, viral suppression may need to be redefined as viral suppression for at least five to six years or at minimum for a period of two or three years of ART with CD4 counts $\geq 200$ cells $/ \mathrm{mm}^{3}$, which is consistent with current viral load monitoring and treatment recommendations $[22,26]$.

Consistent with the HIV literature [15, 27, 28], New Yorkers in this study with a transmission risk history of IDU as well as racial and ethnic minorities were more likely to experience virologic failure while MSM and older adults were less likely to do so. This may, in part, be due to the relationship between social determinants of health and viral suppression. Studies that capture the impact of social determinants of health on viral suppression indicate that factors such as racism, stigma, lack of or poor quality health insurance, and 
poverty contribute to lower rates of viral suppression $[22,29$, 30]. The specific impact of health insurance status on viral suppression is mixed; some studies demonstrate increases in viral suppression rates [31-33] while others have found no association [34]. Among persons with a history of IDU social determinants of health have been associated with increased rates of virologic failure [35]. They have also been identified as likely drivers of HIV outbreaks in this population [35]. Likewise, racial and ethnic minorities are more likely to experience the impacts of systemic racism leading to decreases in viral suppression rates [36-38]. Currently, the National HIV Surveillance System does not systematically collect individual-level data on social determinants of health. Therefore, we could not explore the contribution of individual-level social determinants of health on virologic failure observed in this study. Addressing social determinants of health may lead to increases in viral suppression rates, ultimately contributing to ending the HIV epidemic.

\section{Implications for Policy}

Our findings with regard to virologic failure support the need for ongoing risk reduction activities—such as condom use and pre-exposure prophylaxis to prevent forward HIV transmission [1, 14]. Although current $\mathrm{U}=\mathrm{U}$ messaging emphasizes that PLWDH should achieve and maintain an undetectable viral load for at least 6 months prior to engaging in unprotected sexual intercourse [1, 14], our results indicate that roughly one in five had an unsuppressed viral load within six months of having consecutively suppressed viral load tests and the majority had an unsuppressed viral load result between one and four years. Thus, on-going viral load monitoring by medical providers and public health officials is warranted.

\section{Limitations}

The Prevention Access Campaign, as well as NYS's $\mathrm{U}=\mathrm{U}$ guidelines indicate that persons living with HIV who achieve viral suppression for at least six months have a negligible risk of sexually transmitting HIV [1, 14]. The present study required that the last two consecutive VL results be $<200$ copies $/ \mathrm{mL}$ with no lower time restriction between entry tests (e.g., 90 days between suppressed VLs). This may have resulted in the $34 \%$ virologic failure rate by artificially allowing more individuals to enter into the study population. However, over $80 \%$ of individuals who experienced virologic failure did so after six months of sustained viral suppression. Therefore, it is unlikely that the inclusion criteria had a strong negative effect on the proportion who experienced virologic failure. Some individuals who were censored with a gap in care $\geq 420$ days may have received
VL testing that was not reported to the NYSDOH HIV surveillance system. This likely represents a minimal number of test results as biannual surveys are conducted with laboratories to identify and reconcile potential gaps in HIV-related laboratory reporting. Although $<200$ copies $/ \mathrm{mL}$ is a widely accepted measure of viral suppression [17, 26], research indicates the threshold of HIV-RNA needed to transmit the virus may be between 1000 and 1500 copies/mL [10, 39]. By using $\geq 200$ copies/mL to define virologic failure, our definition more closely resembles surveillance studies than transmissibility studies. Because the literature suggest that most viral blips have a mean viral load of $<50$ copies $/ \mathrm{mL}$ [40, 41], using the surveillance definition of $\geq 200$ copies/ $\mathrm{mL}$ was thought to be a reasonable approach to define viral suppression. Prolonged increases in plasma HIV VL after an extended period of suppression remain a concern for physicians and patients, as they are often a sign of treatment failure or lack of adherence to a treatment regimen. This study could be replicated using a threshold of 1000-1500 copies/ $\mathrm{mL}$ to gain an understanding of how many people experience virologic failure at levels above a transmissibility threshold.

\section{Conclusion}

Despite overall high levels of viral suppression, PLWDH in NYS had high rates of virologic failure, even after achieving consecutive viral suppression. These findings support $\mathrm{U}=\mathrm{U}$ messaging that emphasizes the need for ongoing VL monitoring, adherence support, and engagement in risk reduction activities to prevent forward HIV transmission. Interventions to address ways to decrease virologic failure are necessary, even for PLWDH who have achieved consecutive viral suppression and maintained it for an extended period of time.

Acknowledgements The authors would like to acknowledge the hard work of AIDS Institute staff at the New York State Department of Health. In particular, the Division of HIV/STI Epidemiology, Evaluation and Partner Services; Division of HIV and Hepatitis Health Care; and the Division of HIV/STD/HCV Prevention who coordinated efforts to respond to clusters.

Authors' Contributions JKLG, WP, and CAS conceptualized the work, analyzed the data, and drafted the manuscript. BJA conceptualized the work and contributed to the drafting of the manuscript.

Funding This analysis was made possible through the support of the Centers for Disease Control and Prevention PS18-1802 Integrated Human Immunodeficiency Virus (HIV) Surveillance and Prevention Programs for Health Departments and Improving Sexually Transmitted Disease Programs through Assessment, Assurance, Policy Development and Prevention Strategies (STD AAPPS) Grant (\#H25/ PS004347-03).

Data Availability Data will not be deposited. 
Code Availability The SAS code will not be deposited but is available upon request.

\section{Compliance with Ethical Standards}

Conflict of interest The authors have no conflicts to disclose.

Open Access This article is licensed under a Creative Commons Attribution 4.0 International License, which permits use, sharing, adaptation, distribution and reproduction in any medium or format, as long as you give appropriate credit to the original author(s) and the source, provide a link to the Creative Commons licence, and indicate if changes were made. The images or other third party material in this article are included in the article's Creative Commons licence, unless indicated otherwise in a credit line to the material. If material is not included in the article's Creative Commons licence and your intended use is not permitted by statutory regulation or exceeds the permitted use, you will need to obtain permission directly from the copyright holder. To view a copy of this licence, visit http://creativecommons.org/licenses/by/4.0/.

\section{References}

1. Prevention Access Campaign. Consensus statement 2016 [Available from: https://www.preventionaccess.org/consensus.

2. Prevention Access Campaign. Undectable $=$ Untransmittable 2019 [05/12/2019]. Available from: https://www.preventionaccess.org/ undetectable.

3. Barreiro P, del Romero J, Leal M, Hernando V, Asencio R, de Mendoza C, et al. Natural pregnancies in HIV-serodiscordant couples receiving successful antiretroviral therapy. J Acquir Immune Defic Syndr. 2006;43(3):324-6.

4. Bavinton BR, Jin F, Prestage G, Zablotska I, Koelsch KK, Phanuphak N, et al. The Opposites Attract Study of viral load, HIV treatment and HIV transmission in serodiscordant homosexual male couples: design and methods. BMC Public Health. 2014;14(1):917.

5. Philpot SP, Prestage G, Ellard J, Grulich AE, Bavinton BR, Grulich AE, et al. How do gay serodiscordant couples in Sydney, Australia negotiate undetectable viral load for HIV prevention? AIDS Behav. 2018.

6. Castilla J, Del Romero J, Hernando V, Marincovich B, García S, Rodríguez C. Effectiveness of highly active antiretroviral therapy in reducing heterosexual transmission of HIV. J Acquir Immune Defic Syndr. 2005;40(1):96-101.

7. Cohen MS, Chen YQ, McCauley M, Gamble T, Hosseinipour MC, Kumarasamy N, et al. Prevention of HIV-1 infection with early antiretroviral therapy. N Engl J Med. 2011;365(6):493-505.

8. Cohen MS, Chen YQ, McCauley M, Gamble T, Hosseinipour MC, Kumarasamy N, et al. Antiretroviral therapy for the prevention of HIV-1 transmission. N Engl J Med. 2016;375(9):830-9.

9. Grinsztejn B, Hosseinipour MC, Ribaudo HJ, Swindells S, Eron $\mathrm{J}$, Chen YQ, et al. Effects of early versus delayed initiation of antiretroviral treatment on clinical outcomes of HIV-1 infection: results from the phase 3 HPTN 052 randomised controlled trial. Lancet Infect Dis. 2014;14(4):281-90.

10. Quinn TC, Wawer MJ, Sewankambo N, Serwadda D, Li C, Wabwire-Mangen F, et al. Viral load and heterosexual transmission of human immunodeficiency virus type 1 . N Engl J Med. 2000;342(13):921-9.

11. Rodger AJ, Cambiano V, Bruun T, Vernazza P, Collins S, Van Lunzen J, et al. Sexual activity without condoms and risk of HIV transmission in serodifferent couples when the HIV-positive partner is using suppressive antiretroviral therapy. JAMA. 2016;316(2):171-81.

12. Bavinton BR, Pinto AN, Phanuphak N, Grinsztejn B, Prestage GP, Zablotska-Manos IB, et al. Viral suppression and HIV transmission in serodiscordant male couples: an international, prospective, observational, cohort study. The Lancet HIV. 2018;5(8):e438-47.

13. The Lancet HIV. U $=\mathrm{U}$ taking off in 2017. Lancet HIV. 2017;4:e475.

14. New York State Department of Health AIDS Institute. New York State Department of Health AIDS Institute $U=U$ policy statement 2018 [Available from: https://www.health.ny.gov/diseases/aids/ ending_the_epidemic/docs/u=u/policy_statement.pdf.

15. Centers for Disease Control and Prevention. Monitoring selected national HIV prevention and care objectives by using HIV surveillance data-United States and 6 dependent areas, 2016: HIV Surveillance Supplemental Report; 2018 [

16. Gibert CL. Treatment guidelines for the use of antiretroviral agents in HIV-infected adults and adolescents: An update. 2016;33(Suppl 3):31S.

17. Medland NA, McMahon JH, Chow EP, Elliott JH, Hoy JF, Fairley CK. The HIV care cascade: a systematic review of data sources, methodology and comparability. J Int AIDS Soc. 2015;18(1):20634.

18. Marks G, Patel U, Stirratt MJ, Mugavero MJ, Mathews WC, Giordano TP, et al. Single viral load measurements overestimate stable viral suppression among HIV patients in care: clinical and public health implications. 2016;73(2):205.

19. Sabharwal CJ, Braunstein SL, Robbins RS, Shepard CW. Optimizing the use of surveillance data for monitoring the care status of persons recently diagnosed with HIV in NYC. J Acquir Immune Defic Syndr. 2014;65(5):571-8.

20. Centers for Disease Control and Prevention. Classification system for human immunodeficiency virus (HIV) infection in children under 13 years of age. MMWR. 1987;36(15):225-30.

21. Centers for Disease Control and Prevention. eHARS v4.10 Technical Reference Guide. 2018.

22. Benator DA, Elmi A, Rodriguez MD, Gale HB, Kan VL, Hoffman HJ, et al. True durability: HIV virologic suppression in an urban clinic and implications for timing of intensive adherence efforts and viral load monitoring. AIDS Behav. 2015;19(4):594-600.

23. Benzie AA, Bansi LK, Sabin CA, Portsmouth S, Hill T, Johnson $\mathrm{M}$, et al. Increased duration of viral suppression is associated with lower viral rebound rates in patients with previous treatment failures. AIDS. 2007;21(11):1423-30.

24. Doyle T, Smith C, Vitiello P, Cambiano V, Johnson M, Owen A, et al. Plasma HIV-1 RNA detection below 50 copies $/ \mathrm{ml}$ and risk of virologic rebound in patients receiving highly active antiretroviral therapy. Clin Infect Dis. 2012;54(5):724-32.

25. Martin-Blondel G, Sauné K, Hai VV, Marchou B, Delobel P, Izopet $\mathbf{J}$, et al. Factors associated with a strictly undetectable viral load in HIV-1-infected patients. HIV Med. 2012;13(9):568-73.

26. Panel on Antiretroviral Guidelines for Adults and Adolescents. Guidelines for the use of antiretroviral agents in HIV-1-infected adults and adolescents. Department of Health and Human Services. [Available from: https://aidsinfo.nih.gov/contentfiles/lvgui delines/adultandadolescentgl.pdf.

27. New York State Department of Health AIDS Institute. HIV Care in New York State, 2015: Linkage, retention and viral suppression among persons residing in New York State 2016 [Available from: https://www.health.ny.gov/diseases/aids/general/statistics/casca de_reports/docs/linkage_retention_2015.pdf.

28. New York State Department of Health AIDS Institute. HIV care in New York State, 2016: Linkage to care and viral suppression among persons residing in New York State 2017 [Available from: https://www.health.ny.gov/diseases/aids/general/statistics/casca de_reports/docs/linkage_retention_2016.pdf. 
29. Chen RY, Accortt NA, Westfall AO, Mugavero MJ, Raper JL, Cloud GA, et al. Distribution of health care expenditures for HIVinfected patients. Clin Infect Dis. 2006;42(7):1003-10.

30. Martin LR, Williams SL, Haskard KB, DiMatteo MR. The challenge of patient adherence. Ther Clin Risk Manag. 2005;1(3):189.

31. Jeffries WL, Henny KD. From Epidemiology to Action: The Case for Addressing Social Determinants of Health to End HIV in the Southern United States. AIDS Behav. 2019;23(3):340-6.

32. Rojas D, Melo A, Moise IK, Saavedra J, Szapocznik J. The Association Between the Social Determinants of Health and HIV Control in Miami-Dade County ZIP Codes, 2017. J Racial Ethn Health Disparities. 2020.

33. Benson C, Wang X, Dunn KJ, Li N, Mesana L, Lai J, et al. Antiretroviral Adherence, Drug Resistance, and the Impact of Social Determinants of Health in HIV-1 Patients in the US. AIDS Behav. 2020;24(12):3562-73.

34. Raifman J, Althoff K, Rebeiro PF, Mathews WC, Cheever LW, Hauck H, et al. Human Immunodeficiency Virus (HIV) Viral Suppression After Transition From Having No Healthcare Coverage and Relying on Ryan White HIV/AIDS Program Support to Medicaid or Private Health Insurance. Clin Infect Dis. 2019;69(3):538-41.

35. Kim MM, Conyngham SC, Smith C, Higgins D, Nassau T, Terrell $\mathrm{C}$, et al. Understanding the Intersection of Behavioral Risk and Social Determinants of Health and the Impact on an Outbreak of Human Immunodeficiency Virus Among Persons Who Inject Drugs in Philadelphia. J Infect Dis. 2020;222(5):S250-8.

36. Doshi RK, Bowleg L, Blankenship KM. Tying Structural Racism to HIV Viral Suppression. Clin Infect Dis. 2020.
37. Randolph SD, Golin C, Welgus H, Lightfoot AF, Harding CJ, Riggins LF. How Perceived Structural Racism and Discrimination and Medical Mistrust in the Health System Influences Participation in HIV Health Services for Black Women Living in the United States South: A Qualitative, Descriptive Study. J Assoc Nurses AIDS Care. 2020;31(5):598-605.

38. Freeman R, Gwadz MV, Silverman E, Kutnick A, Leonard NR, Ritchie AS, et al. Critical race theory as a tool for understanding poor engagement along the HIV care continuum among African American/Black and Hispanic persons living with HIV in the United States: a qualitative exploration. Int J Equity Health. 2017;16(1):54.

39. Loannidis JP, Abrams EJ, Ammann A, Bulterys M, Goedert JJ, Gray L, et al. Perinatal transmission of human immunodeficiency virus type 1 by pregnant women with RNA virus loads $<1000$ copies/ml. J Infect Dis. 2001;183(4):539-45.

40. Lee PK, Kieffer TL, Siliciano RF, Nettles RE. HIV-1 viral load blips are of limited clinical significance. J Antimicrob Chemother. 2006;57(5):803-5.

41. Porter DP, Kulkarni R, Garner W, Miller MD, White KL. Viral blips were infrequent in treatment-naive adults treated with rilpivirine/emtricitabine/tenofovir DF or efavirenz/emtricitabine/tenofovir DF through 96 weeks. Antivir Ther. 2017;22(6):495-502.

Publisher's Note Springer Nature remains neutral with regard to jurisdictional claims in published maps and institutional affiliations. 